\title{
Assessment of Groundwater Vulnerability to Pollution using DRASTIC Model and Fuzzy Logic in Herat City, Afghanistan
}

\author{
Nasir Ahmad Gesim ${ }^{1}$ \\ Graduate School of Engineering and Science \\ University of the Ryukyus \\ Okinawa, Japan
}

\author{
Takeo Okazaki² \\ Computer Science \& Intelligent Systems \\ University of the Ryukyus \\ Okinawa, Japan
}

\begin{abstract}
Groundwater (GW) vulnerability maps have become a standard tool for protecting groundwater resources from pollution because, from one hand groundwater represents the main source of drinking water, and on the other hand high concentrations of human activities such as industrial, agricultural, and household represent real or potential sources of groundwater contamination. The main objective of this study is to assess the groundwater vulnerable zones in Herat city, which is the second fastest growing big city in Afghanistan, using the DRASTIC model and fuzzy logic. DRASTIC is based on the seven data layers i.e. Depth of water, net Recharge, Aquifer media, Soil media, Topography, Impact of vadose zone and hydraulic Conductivity that provide the input to the modeling. The study shows that $51 \%$ of the city's groundwater is under highly vulnerable to water pollution. Validation of model showed that vulnerability map which integrated by kriging interpolated layers has better accuracy than inverse distance weighing (IDW) method. The study suggests, that the proposed model can be an effective tool for local authorities who are responsible for managing groundwater resources especially in Afghanistan and assigning rating value of DRASTIC parameters using inference system of fuzzy logic.
\end{abstract}

Keywords-Afghanistan; DRASTIC; de-fuzzification; groundwater; modeling; vulnerability; herat

\section{INTRODUCTION}

Most of GW related problems generally focus on the water contamination and quality reduction which depend to factors such as urbanization, industrialization, irregular use of fertilizers and pesticides in agriculture, nonstandard disposal of wastewater and increment of population. Groundwater quality protection is a vital and important theme specially, in high growing urban areas. because $\mathrm{GW}$ is the only major source of water for drinking and industrial activities. GW quality concerns can cause big problems for communities, if there is not be a specific and precise plan for protection and monitoring of it. Because from one hand the cost of reducing groundwater contaminants is not cheap and from other hand it may take long time. Therefore, it is necessity to define which systems and hydrogeological models are most suitable to use for groundwater quality protection. GW vulnerability assessment can be noted as a preventive function for protection of $\mathrm{GW}$ quality prior to start monitoring of groundwater resource in the area. This approach has been widely used for GW vulnerability to pollution.

Afghanistan's climate is arid to semi-arid where the weather is cold in winter and hot and dry in summer with temperature that ranges from $-20^{\circ} \mathrm{C}$ in winter to $50^{\circ} \mathrm{C}$ in summer. The drinking water quality in Afghanistan's big cities has been deteriorating in recent years mainly due to the high growth of population, agricultural activities, septic tanks system and municipal wastes [1]. Most of the cities and towns do not have central sewer line systems, there are just individual septic tanks installed for each house. These tanks are not constructed in a sanitary condition and standard distance from drinking water well to prevent infiltration of wastewater into the groundwater.

\section{RESEARCH PROPOSED}

Better cognition of groundwater importance caused that groundwater manager and policy maker in the world attempting to prevent and reduce groundwater contamination by analyzing effective factors. Unfortunately, there is few researches regarding groundwater vulnerability in Afghanistan yet, and since lack of GW vulnerability assessment may increase groundwater pollution in big cities like Herat, so the main goal of this study is to assess GW vulnerability to pollution using the DRASTIC model [2] and fuzzy logic [3] in Herat city Afghanistan.

\section{RELATIONAL STUDIES}

There are various concepts to assess GW vulnerability. Generally, they consist process-based methods, statistical methods, and overlay and index methods [4]. The processbased methods use simulation models to estimate the contaminant transmission. Disadvantages of these methods are data shortage and computational difficulties [5]. Statistical methods use statistics such as clustering, frequency ratio and scoring equations to establish a relationship between spatial variables and actual occurrence of contaminant in the aquifer. Careful choosing of spatial variables, data accuracy and insufficient observation points can be noted as limitations of these methods. The main advantage of Overlay and index methods which integrate parameters controlling the movement of contaminants from the ground surface into the saturated zone resulting in vulnerability indices at different locations is 
that, all the parameters such as net recharge and hydraulic conductivity and water level can be available for wide areas, that is why these methods are more suitable for vulnerability assessments than two others methods [6].

In the overlay and index methods there are different methods like DRASTIC, GOD [7], SINTACS [8] and SI [9] methods but among them DRASTIC has been used more for GW vulnerability assessment. This model dose not predict the occurrence of $\mathrm{GW}$ pollution. The merit of the overlay and index method such as that used by DRASTIC is that changes can be easily made [10]. Combination of Fuzzy rules and DRASTIC model provide comparable results with less input data and has been caused for improvement of vulnerability prediction [11]. A GW vulnerability assessment methodology that needs less field data, is robust and useful screening tool when less data is available. Khemiri et al, [12] compared DRASTIC, GOD, SINTACS and SI method for assessment of GW vulnerability to pollution in scenarios of semi-arid climate in Foussan in the central of Tunisia. The output of his comparison showed that DRASTIC model is more suitable in semi-arid climate. Xiaoyu et al, [13] applied modified DRASTIC model for assessment of groundwater vulnerability in Beihai City, China. This study modified the rating of DRASTIC parameters based on the local environmental conditions and weight of parameters assigned by analytic hierarchy process (AHP) to reduce the subjectivity of humans to vulnerability assessment; Maryam Hosseini, [14] used Modified DRASTIC and GOD models for assessment and estimating GW vulnerability to pollution in Malayer Plain of Iran. In This study ranking and weighing of nitrate pollutant inserted in DRASTIC equation and zoning map of DRASTIC has been calibrated by nitrate concentration also, this method showed that DRASTIC model has more accuracy than GOD model in arid and semi-arid climate.

\section{RESEARCH AREA}

Herat city which has been chosen as research area in this study located in the center of Herat province, Afghanistan between $\left(34.248^{\circ}\right.$ and $\left.34.474^{\circ}\right)$ latitudes, and $\left(61.942^{\circ}\right.$ and $62.442^{\circ}$ ) longitudes with an area of $730 \mathrm{~km}^{2}$. The altitude in the research area ranges from 858 to 1636 above sea level. The average annual precipitation is $210 \mathrm{~mm}$. GW resources in the study area include qanat, springs, and deep and semi-deep wells. The general trend of GW flow is from the east to west.

\section{MATERIALS AND METHOD OF DRASTIC MODEL}

Assessment of GW vulnerability in this study consist of 3 steps. At the first step thematic layers for each DRASTIC parameter were prepared using point data and IDW and Kriging interpolation methods. At the next step as a modification in DRASTIC model fuzzy inference system were used to determine rating value for each class of thematic layers. At the last step conventual DRASTIC algorithm were used to calculate vulnerability index. Validation of the model were done using splitting the research area and comparing with existing nitrate contamination in the research area.

\section{A. DRASTIC Model}

DRASTIC model as a standard system for assessing GW vulnerability to pollution was used here in this study.
Availability of input required information from various government departments can be noted as advantage of this model. DRASTIC model is based on seven parameters which to be used as input parameters for modeling. For each DRASTIC parameters a thematic layer to be prepared. Then each thematic layer should be classified into ranges based on its media types, which have an influence on vulnerability. Membership degree of thematic layers determined here by fuzzy inference system. The assigned Weight of DRASTIC model are then used for each factor to balance and increase its importance. The final vulnerability map is based on the DRASTIC index (Di) which is computed as the weighted sum overlay of the seven layers using (1):

$D_{i}=D_{r} \times D_{w}+R_{r} \times R_{w}+A_{r} \times A_{w}+S_{r} \times S_{w}+T_{r} \times T_{w}+I_{r} \times I_{r}+C_{r} \times C_{w}$

Where, D, R, A, S, T, I and C are the seven parameters, $r$ is the rating value, and $\mathrm{w}$ the weight assigned to each parameter. Each parameter in the model has a fixed weight indicating the relative influence of the parameter in transporting contaminants to $\mathrm{GW}$. Weights vary from 1 to 5 [15], with higher values describing greater vulnerability. Also, ratings vary from 0 to 1 , with higher value describing grater vulnerability. In this study, de-fuzzification method of fuzzy logic used instead of empirical method to scientifically determine rating values for different classes of thematic layers [16]. Fig. 1 shows the flowchart of the DRASTIC model which indicates the following process:

- Using seven types of raw data at the first step

- Converting raw data to thematic layers map using interpolation, Clipping and DEM classification methods.

- Integrating reclassified thematic layers using conventional DRASTCI algorithm.

\section{B. Mapping}

To prepare thematic layers of DRASTIC parameters based on the point data, IDW [17] and Kriging [18] interpolation methods were picked up. The main objective behind using two interpolation methods is, to know which one of them has better accuracy in DRASTIC model of GW vulnerability assessment.

To predict a value for an unknown point, IDW uses the known values surrounding the prediction point. The known values closest to the prediction location have more impact on the predicted value than those farther away. IDW assumes that each known point has a local impact that diminishes with distance. The prediction values are calculated by (2):

$$
V_{p}=\sum_{i=1}^{n}\left(v_{i} / d_{i}\right) / \sum_{i=1}^{n}\left(1 / d_{i}\right)
$$

Where, $V_{p}$ is prediction value, $v_{i}$ is measured value and $d_{i}$ is distance between prediction location and location of measured values . 
Kriging is a statistical method that uses of a variograms to calculate the spatial autocorrelation between points at graduated distances to determine the weights that should be applied at various distances. As with IDW interpolation, the known values closest to the unknown locations have the most impact. But differs in that weights are helped determined by the semi variogram as (3):

$\gamma(h)=\sum_{i=1}^{N}\left[Z\left(x_{i}+h\right)-Z\left(x_{i}\right)\right]^{2} / 2 N$

Where, $\mathrm{N}$ is the number of pairs of sample points of observations, $\mathrm{z}$ is the attribute separated against distance $\mathrm{h}$ and $x_{i}$ is known value.

\section{Thematic Layers}

Thematic layers of all parameters expect soil media and slope percent were prepared using point data and IDW and Kriging interpolation methods. To prepare soil media and topography layers, soil shape data of Afghanistan and Digital Elevation Model (DEM) were used, respectively.

Depth to GW can be counted as one of the most important factors which has effect on GW vulnerability because it directly depends to the thickness of material which located above aquifer. The water must travel through this material before reaching to the aquifer saturated zone. In general, GW vulnerability increases with depth to GW. Depth to GW maps prepared and classified in 6 classes.

Recharge water is a significant vehicle for percolating and transporting contaminants within the vadose zone to the saturated zone. It carries the solid and liquid contaminants to the water table and increases the water tables. The net recharge layer prepared using rise method of water-table fluctuations
[19]. This method provides a point value of recharge calculated from the water-level rise in a well multiplied by the specific yield $(S Y)$ of the aquifer equation as shown in (4).

$$
R=S Y \times \Delta H
$$

Where, $\mathrm{R}$ is point value of recharge, $\mathrm{SY}$ is the ratio of the volume of water obtained by draining a sample of saturated rock or soil $V_{w}$ to the gross volume of the sample $V_{m}$.

$$
S Y=V_{w} / V_{m}
$$

$\Delta \mathrm{H}$ is annual water level change. Based on the SY of each monitoring well [20] and $\Delta \mathrm{H}$ from Dec 2016 to Dec 2017. Net recharge maps of research area were prepared and classified in 7 classes.

The presence of fine grain size materials, such as clay, peat, or silt, and the percentage of organic matter within the soil cover can decrease intrinsic permeability, and retard or prevent contaminant migration via physical-chemical processes. The soil map was prepared from the Afghanistan soil shape data [21].

The contaminant attenuation of the aquifer depends on the amount and sorting of fine grains. The aquifer media map was prepared from the well $\log$ and classified in 9 classes.

Aquifer hydraulic conductivity is the ability of the aquifer formation to transmit water. Grain size method was used to estimate the hydraulic conductivity of aquifer by the Hazen approximation [22]:

$$
K=C \times D_{10}^{2}
$$

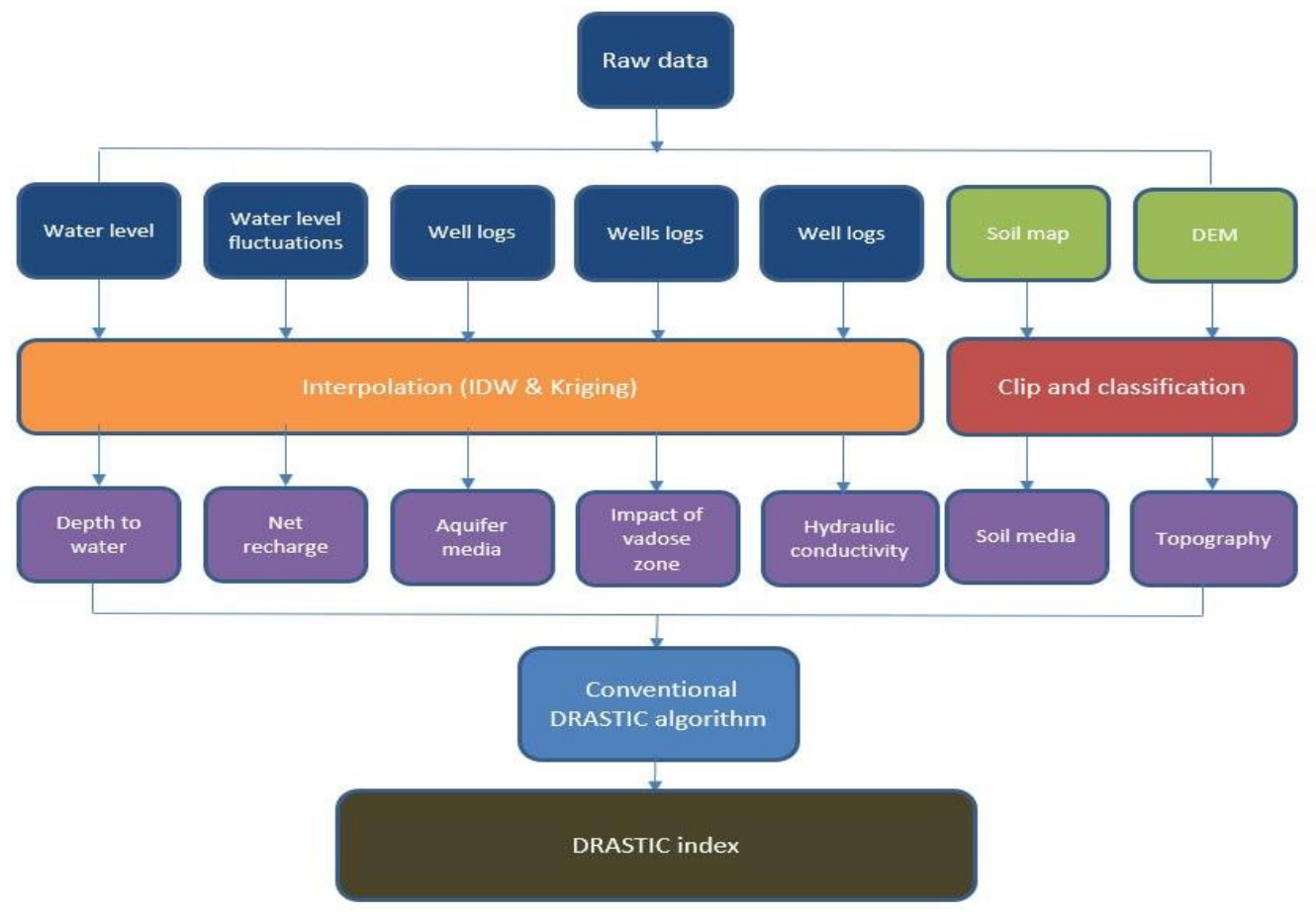

Fig. 1. Flow Chart of DRASTIC Model. 
Where $\mathrm{K}$ is hydraulic conductivity in $\mathrm{cm} / \mathrm{sec}, \mathrm{C}$ is Hazen coefficient, (0.8-1.2) typically $1[23]$ and D is the diameter of the 10-percentile grain size of the material. Hydraulic conductivity in research area is classified in 9 classes.
The vadose zone has a high impact on water movement if it is composed of a permeable material. Impact of vadose zone was prepared from well-log which classified in 9 classes.

TABLE I. Weight AND RATing VALUe OF Thematic LAyers

\begin{tabular}{|c|c|c|c|}
\hline Layer & $\mathbf{w}$ & Class & $\mathbf{r}$ \\
\hline \multirow{6}{*}{ Depth to water(m) } & \multirow{6}{*}{5} & $(0-4)$ & 0.77 \\
\hline & & $(4.1-15)$ & 0.59 \\
\hline & & $(15-25)$ & 0.31 \\
\hline & & $(25-35)$ & 0.11 \\
\hline & & $(35-45)$ & 0.04 \\
\hline & & $(45-63)$ & 0.03 \\
\hline \multirow{7}{*}{$\begin{array}{l}\text { Net Recharge } \\
\text { (mm/year) }\end{array}$} & \multirow{7}{*}{4} & $(-17-12)$ & 0.3 \\
\hline & & $(12-27)$ & 0.37 \\
\hline & & $(27-34)$ & 0.4 \\
\hline & & $(34-48)$ & 0.45 \\
\hline & & $(48-79)$ & 0.57 \\
\hline & & $(79-144)$ & 0.7 \\
\hline & & $(144-283)$ & 0.8 \\
\hline \multirow{9}{*}{ Aquifer media } & \multirow{9}{*}{3} & compacted clay, Very hard gravel & 0.14 \\
\hline & & Cobble Gravel \& sand & 0.22 \\
\hline & & compact sand, silty clay & 0.32 \\
\hline & & Sandy gravel, clay & 0.44 \\
\hline & & Sandy gravel, silty Clay & 0.56 \\
\hline & & Sandy gravel & 0.69 \\
\hline & & Sandy gravel, gravel & 0.78 \\
\hline & & gravel & 0.8 \\
\hline & & large gravel & 0.84 \\
\hline \multirow{4}{*}{ Soil media } & \multirow{4}{*}{2} & fine grained \& coarse-grained soils: clay \& silty sand (shallow), silt \& clay (moderately deep to deep) & 0.64 \\
\hline & & fine grained \& coarse-grained soils: gravel overlain by clay & 0.35 \\
\hline & & coarse grained: gravel overlain by silty sand and clayey sand & 0.85 \\
\hline & & fine grained soils: clay underlain by gravel and silty sand & 0.16 \\
\hline \multirow{5}{*}{$\begin{array}{r}\text { Topography } \\
\text { (slope\%) }\end{array}$} & \multirow{5}{*}{1} & $<5$ & 0.72 \\
\hline & & $(5-10)$ & 0.63 \\
\hline & & $(10-18)$ & 0.47 \\
\hline & & $(18-30)$ & 0.29 \\
\hline & & $>30$ & 0.15 \\
\hline \multirow{9}{*}{$\begin{array}{l}\text { Impact of Vadose } \\
\text { zone media }\end{array}$} & \multirow{9}{*}{5} & clay & 0.09 \\
\hline & & Sandy \& Silty Clay & 0.2 \\
\hline & & Sandy gravel, clay & 0.26 \\
\hline & & Silty sand & 0.39 \\
\hline & & clay, gravel & 0.4 \\
\hline & & Silty Clay \& gravel, sandy gravel & 0.43 \\
\hline & & Silty clay \& gravel & 0.55 \\
\hline & & gravel & 0.77 \\
\hline & & Large gravel & 0.91 \\
\hline \multirow{9}{*}{$\begin{array}{l}\text { Hydraulic } \\
\text { Conductivity } \\
(\mathrm{cm} / \mathrm{sec})\end{array}$} & \multirow{9}{*}{3} & $(4-131)$ & 0.14 \\
\hline & & $(131-258)$ & 0.2 \\
\hline & & $(258-385)$ & 0.27 \\
\hline & & $(385-512)$ & 0.37 \\
\hline & & $(512-639)$ & 0.45 \\
\hline & & $(639-766)$ & 0.54 \\
\hline & & $(766-893)$ & 0.62 \\
\hline & & $(893-1020)$ & 0.77 \\
\hline & & $(1020-1147)$ & 0.92 \\
\hline
\end{tabular}


Topography demonstrates slope of an area. The precipitation water stays in the area with low slop for a long time. This allows a greater infiltration which causes pollution migration. Unlike, Areas with higher slopes have large amounts of runoff, smaller amounts of infiltration and are less vulnerable to GW pollution. The topographic map was prepared from the DEM and it was divided into five classes.

Table. 1 shows rating values for different classes of thematic layers which prepared by centroid method of defuzzification in fuzzy inference system

Then all seven layers reclassified by rating values and integrated by (1). Once the DRASTIC index has been computed, then divided into 3 classes as shown in Fig .2.

\section{VALIDATION}

To validate the model, a comparison between prepared vulnerability maps and existing level of nitrate in research area which recorded by local government in Herat province at the end of 2017 has been done. For this propose, 51 water sample from bore wells interpolated by both IDW and Kriging methods as shown in Fig .3.

Overlaying vulnerability maps by nitrate maps shows that, percentage of contaminated area which exceed permissible limit $(10 \mathrm{mg} / \mathrm{lit})$ and located in high vulnerable zone with Kriging is greater than IDW. Fig.4 and Table 2 show numerical and graphical values of this relationship, respectively. Since high vulnerable zone should be contaminated first, so it seems that Kriging interpolation has better accuracy than IDW.

In addition, to verify this validation, the research area was splinted into west and east parts and the process started from the beginning in west part as 2nd research area. Finally, when vulnerability maps of 2 nd research area overlaid by nitrate maps of 2 nd research area, it shows same results. Fig. 5 and Table 3 show this relationship, respectively.
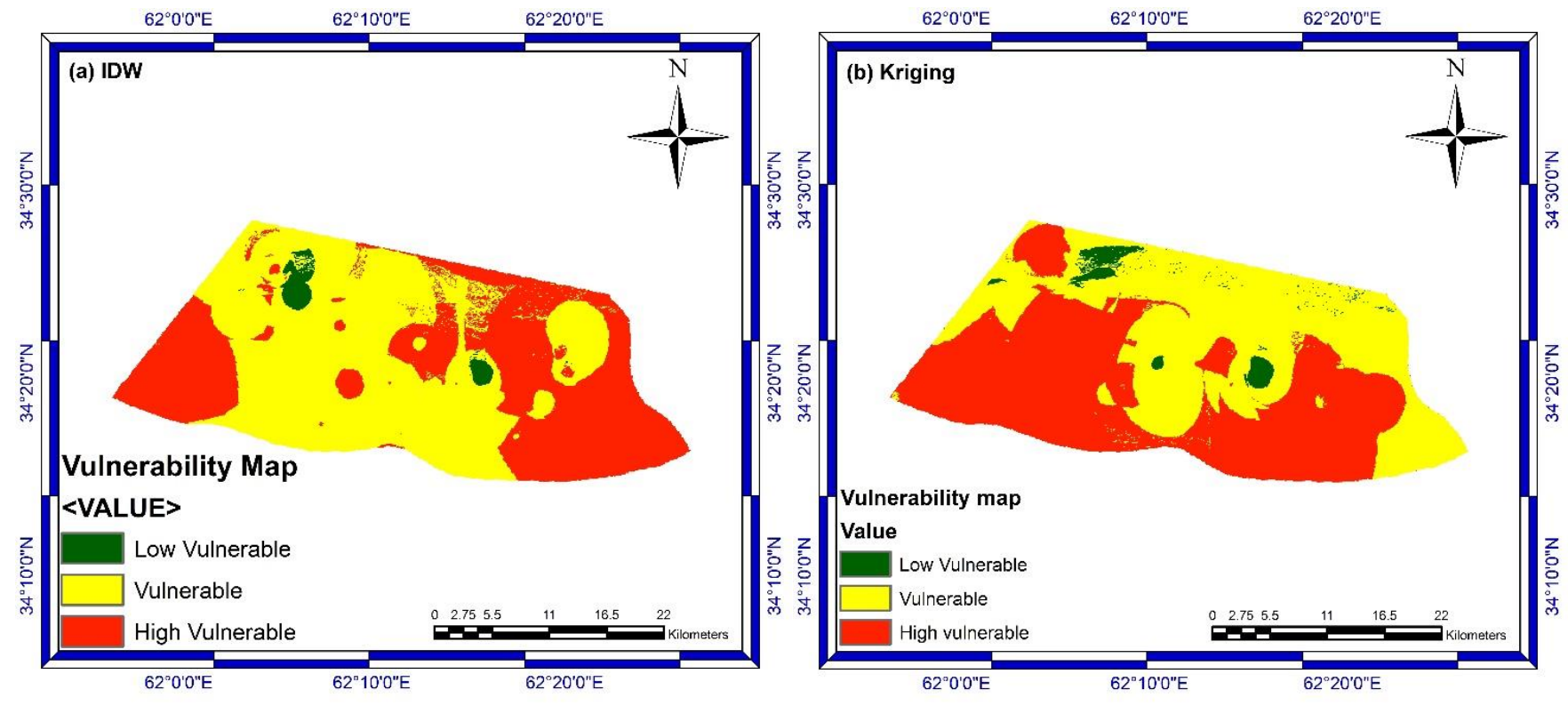

Fig. 2. Vulnerability Maps with IDW and Kriging.
Hence, GW vulnerability map of Fig. 2b which interpolated by Kriging interpolation method and developed by applying DRASTIC model and fuzzy logic to the thematic layers is final goal of this study. The results indicate that GW in Herat city in most parts is in the vulnerable to high vulnerable zones. The vulnerable zones have been classified into low vulnerable, vulnerable, and high vulnerable zones. The study showed that $51.09 \%$ of the total research area in final vulnerability map, i.e. Fig. $2 b$ is under the high vulnerable zone. About $46 \%$ of the area is under vulnerable zone and just $2.9 \%$ of research area has low vulnerability.

\section{CONCLUSION}

Determination of rating value in DRASTIC model using centroid de-fuzzification method of fuzzy logic which is more scientific than conventional empirical method and preparation of DRASTIC parameter using kriging interpolation which showed better accuracy that IDW can be noted as highlight point of this study. This study can assist groundwater manager and local authorities because it gives a very clear classification of groundwater vulnerability to pollution. In the high vulnerable class, it necessary for local authorities manage GW resources, monitor this problem deeply and to act seriously. the risk of GW contaminant can only be reduced by planning, construction, and operation of a standard infiltration systems in the urban area. It can help the urban engineers and decisionmakers while choosing the areas for waste disposal and industrial sites. This study suggests assigning rating value of DRASTIC parameters using fuzzy inference system of fuzzy logic. Furthermore, using the DRASTIC model can also manage monitoring schedule, there should be high and very high vulnerable zones in prioritization in order to check fluctuations of pollutants level and act for reducing of them. The future work includes applying the current study to web application to be easily accessible by local authorities, groundwater researchers and even public users. 

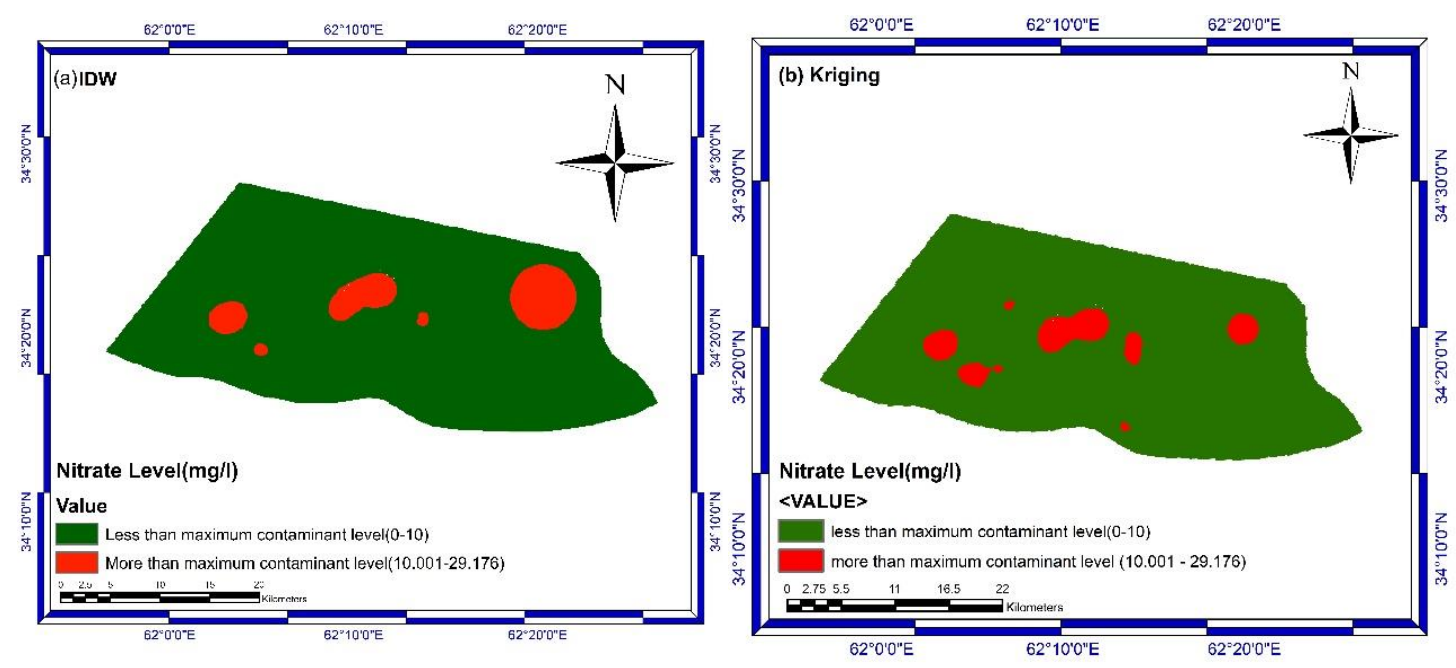

Fig. 3. Nitrate Level Maps with IDW and Kriging.
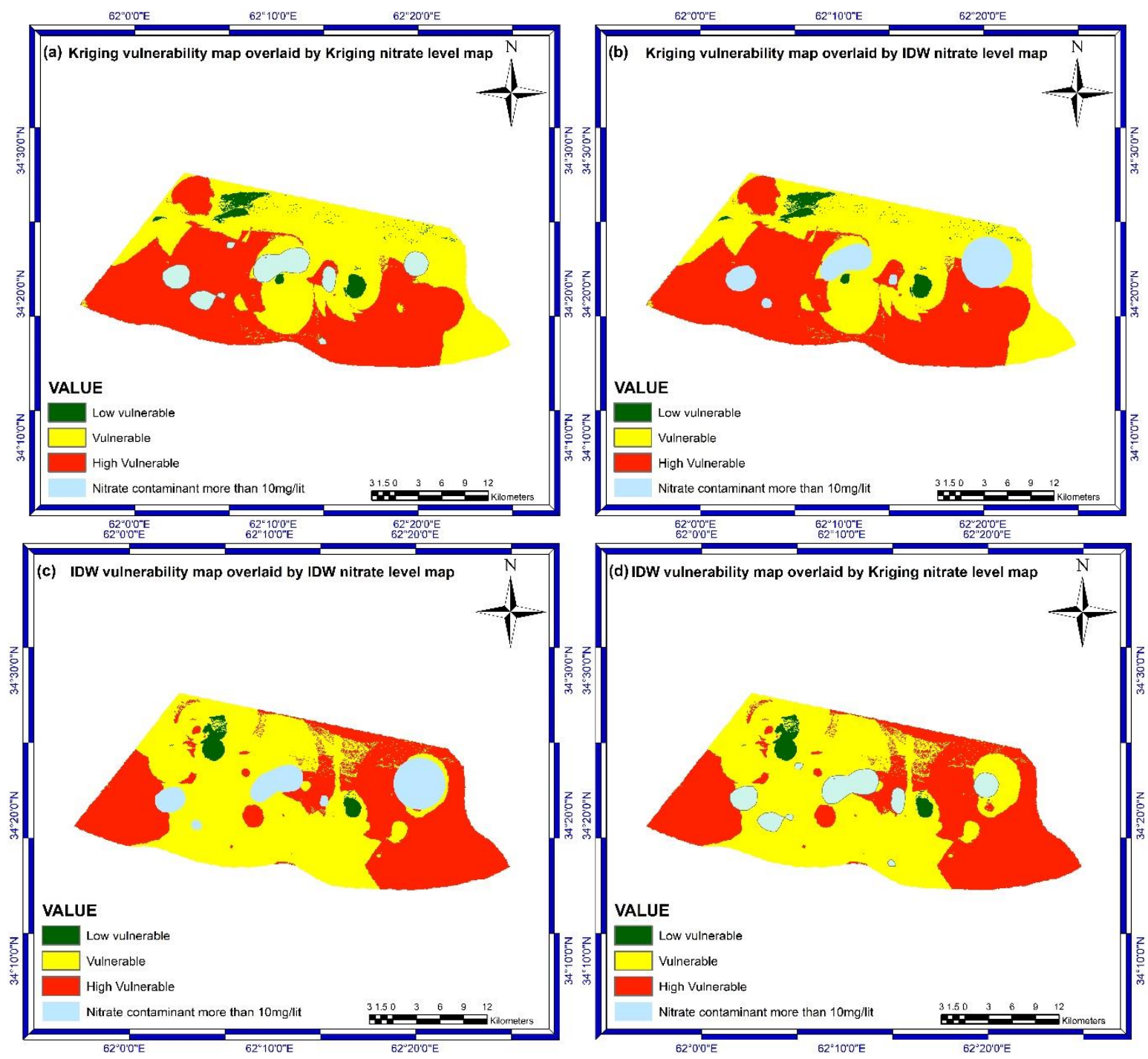

Fig. 4. Validation maps (a) Kriging vulnerability map Overlaid by Kriging nitrate level map(b) K vulnerability map overlaid by IDW nitrate level map(c) IDW vulnerability map overlaid by IDW nitrate level map (d) IDW vulnerability map by Kriging nitrate level map. 
TABLE III. NUMERICAL RELATIONSHIP OF OVERLAP AREAS

\begin{tabular}{|l|l|l|}
\hline Vulnerability Maps (Kriging\& IDW) overlaid by Kriging nitrate map (Fig.4a \&Fig. 4b) \\
\hline \multirow{2}{*}{ Class } & Percentage of contaminated area which exceed permissible limit (10mg/lit) \\
\cline { 2 - 3 } & Kriging & IDW \\
\hline Low Vulnerable & 0.01 & 0.02 \\
\hline Vulnerable & 55.61 & 72.92 \\
\hline High Vulnerable & 44.38 & 27.06 \\
\hline Vulnerability Maps (Kriging\& IDW) overlaid by IDW nitrate map (Fig.4c \&Fig.4d) \\
\hline \multirow{2}{*}{ Class } & Percentage of contaminated area which exceed permissible limit (10mg/lit) \\
\cline { 2 - 3 } & Kriging & IDW \\
\hline Low Vulnerable & 0.12 & 0.04 \\
\hline Vulnerable & 71.1 & 75.78 \\
\hline High Vulnerable & 28.78 & 24.18 \\
\hline
\end{tabular}
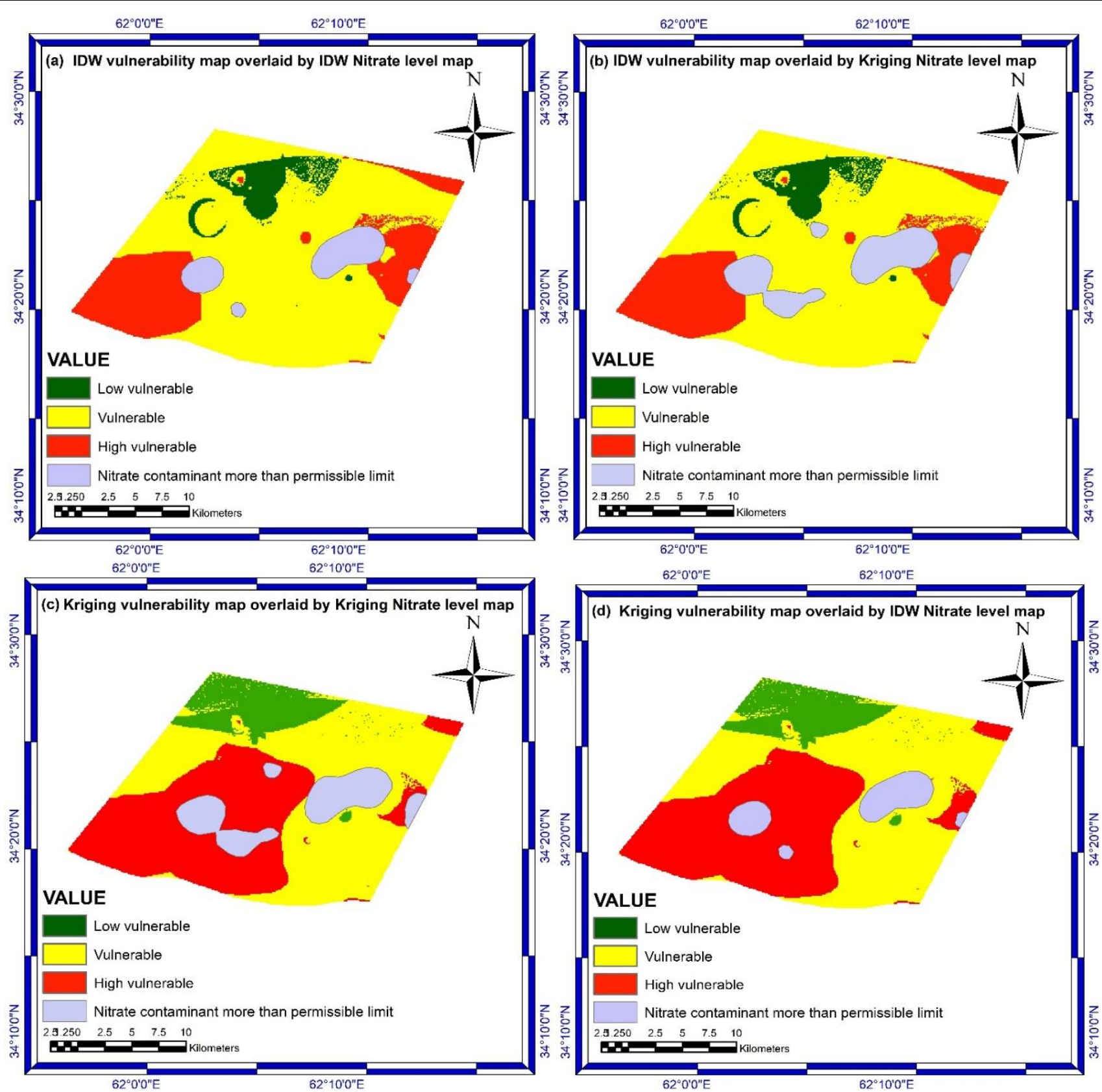

Fig. 5. Validation maps of 2nd research area (a) IDW vulnerability map by IDW nitrate level map(b) IDW vulnerability map by Kriging nitrate level map(c) Kriging vulnerability map by IDW nitrate level map (d) Kriging vulnerability map by IDW nitrate level map. 
TABLE IV. NUMERICAL RELATIONSHIP OF OVERLAP AREAS FOR 2ND RESEARCH AREA

\begin{tabular}{|l|l|l|}
\hline \multicolumn{2}{|l|}{ Vulnerability Maps (IDW\& kriging) overlaid by Kriging nitrate map (Fig. 5b \& Fig. 5c) } \\
\hline \multirow{2}{*}{ Class } & Percentage of contaminated area which exceed permissible limit (10mg/lit) \\
\cline { 2 - 3 } & IDW & \multicolumn{2}{|l|}{ Kriging } \\
\hline Low Vulnerable & 0.16 & 0.15 \\
\hline Vulnerable & 70.48 & 48.5 \\
\hline High Vulnerable & 29.35 & 55.35 \\
\hline Vulnerability Maps (IDW\& kriging) overlaid by IDW nitrate map (Fig. 5a \& Fig. 5d) \\
\hline \multirow{2}{*}{ Class } & Percentage of contaminated area which exceed permissible limit (10mg/lit) \\
\cline { 2 - 3 } & IDW & Kriging \\
\hline Low Vulnerable & 0.13 & 0.12 \\
\hline Vulnerable & 64.83 & 61.71 \\
\hline High Vulnerable & 35.04 & 38.71 \\
\hline
\end{tabular}

\section{REFERENCES}

[1] Ehsanullah Hayat \& Alper Baba, Quality of groundwater resources in Afghanistan Environ Monit Assess, 189: 318, 2017.

[2] US EPA (Environmental Protection Agency). DRASTIC: a standard system for evaluating groundwater potential using hydrogeological settings, WA/EPA Series, p. 163, Ada, Oklahoma, 1985.

[3] Zadeh, L.A,"Fuzzy sets". Information and Control,vol. 8 (3) , pp. 338353, 1965.

[4] Tesoriero AJ, Inkpen E.L, Voss FD, "Assessing ground-water vulnerability using logistic regression". source Water Assessment and Protection 98, Technical Conference Proceedings, pp. 157-165 ,April 1998

[5] Barbash JE, Resek EA. "Pesticides in ground water: distribution, trends, and governing factors"(Chelsea, MI: Ann Arbor Press;1996).

[6] Thapinta A, Hudak PF. Use of geographic information systems for assessing groundwater pollution potential by pesticides in Central Thailand. Environ Int,vol. 29(1), pp. 87-93,2003

[7] Foster, S.S.D. and R. Hirata., "Groundwater Pollution Risk Assessment: A Methodology using Available Data", WHO - PAHO / HPE - CEPIS Technical Manual. WHO: Lima, Peru. 78,1998.

[8] Civita, M, Le Carte délia Vulnerabilitâdegli Acquiferiall'Inqulnamento. TeoriaiPratica (Aquifer vulnerability maps to pollution). Pitagora Ed. (publisher), Bologna, 1994.

[9] Luís Ribeiro, Juan Carlos Pindo, Luis Dominguez-Granda, Assessment of groundwater vulnerability in the Daule aquifer, Ecuador using the susceptibility index method, Science of the Total Environment, vol. 574, 1, pp. 1674-1683, January 2017.

[10] EPA. (2003),Contaminated sediment transport and fate modeling Athens, GA, p. 30605, http://www.epa.gov/nerl/research/2003/ g54.html.

[11] Dixon, B, "Groundwater vulnerability mapping: A GIS and fuzzy rule based integrated tool". Applied Geography, vol. 25(4), pp. 327347,2005 .

[12] Sami Khemiri, Afef Khnissi, Mohsen Ben Alaya1, Salwa Saidi and Fouad Zargouni1, "Using GIS for the Comparison of Intrinsic Parametric Methods Assessment of Groundwater Vulnerability to Pollution in Scenarios of Semi-Arid Climate. The Case of Foussana
Groundwater in the Central of Tunisia”, Journal of Water Resource and Protection, vol. 5, pp. 835-845,2013.

[13] Xiaoyu WUBin LIChuanming MA, "Assessment of groundwater vulnerability by applying the modified DRASTIC model in Beihai City, China", Environmental Science and Pollution Research, vol. 25(13), ,pp. 12713-12727, May 2018.

[14] Maryam Hosseini, Ali Saremi, “Assessment and Estimating Groundwater Vulnerability to Pollution Using a Modified DRASTIC and GODS Models (Case Study: Malayer Plain of Iran)", Civil Engineering Journal, vol. 4(2),pp. 433-442, 2018.

[15] Aller, L, Bennett, T, Lehr, J. H, Petty, R.J, and Hackett G, "DRASTIC: A standardized system for evaluating groundwater pollution potential using hydrogeologic settings", (NWWA/EPA Series, EPA-600/2-87035,1987, $622 \mathrm{p}$ ).

[16] Nasir Ahmad Gesim, Takeo Okazaki, Identification of groundwater artificial recharge sites in Herat city, Afghanistan, using Fuzzy logic, International Journal of Engineering and Technical Research, vol. 8(2), pp. 40-45, 2018.

[17] Paul V. Bolstad, GIS fundamentals 3rd ed, (Eider Press, White Bear Lake, Minnesota, United states ,2007)

[18] Burrough, P. A, "Principles of Geographical Information Systems for Land Resources Assessment",New York: Oxford University Press, 1986.

[19] John R. Nimmo, Charles Horowitz, and Lara Mitchell, "Discrete-Storm Water-Table Fluctuation Method to Estimate Episodic Recharge" Groundwater,vol. 53(2),pp. 282-292,March-April 2015.

[20] A. I. Johnson, "Specific Yield - Compilation of Specific Yields for Various Materials" (U S government printing office, Washington, 1967).

[21] USDA (United States Department of Agriculture), Natural Resources Conservation Service Soils, "Soil Regions Map of Afghanistan", https://www.nrcs.usda.gov/wps/portal/nrcs/detail/soils/use/?cid=nrcs142 p2_054000.

[22] Hazen, A, Discussion of Dams on sand formations, by A.C. Koenig. Transactions of the American Society of Civil Engineers, vol. 73, pp. 199-203, 1911.

[23] Fetter, C.W,Applied Hydrogeology. 4th Edition (Pearson, Higher Education, New Jersey, 2001). 